Artigo Original

\title{
Reuso de águas cinzas: estudo de caso da eficiência de dois tipos de filtros intermi- tentes de areia no tratamento de água cinza sintética
}

\author{
Graywater reuse: case study of the efficiency of two types of intermittent sand filters in the \\ treatment of synthetic gray water
}

\begin{abstract}
Taís Carolina de Oliveira Alcântara', Emerson Renato Maciel da Silva", Caio César Barbosa de Siqueira ${ }^{\prime \prime \prime}$, Laryssa Barbosa Fernandes ${ }^{\mathrm{IV}}$, Philip T McCreanor ${ }^{\mathrm{V}}$, Ivan Carlos da Costa Barbosa ${ }^{\mathrm{VI}}$
\end{abstract}

\section{Resumo}

A água é um recurso renovável e limitado, no entanto sua potabilidade constitui-se um fator imprescindível, visto que devido ao aumento da população de forma desordenada atrelado ao uso indiscriminado de tal recurso promoveu uma ameaça à qualidade da mesma. Afim de buscar soluções simples, sustentáveis e com baixo custo, diversos países, como Estados Unidos, Japão e alguns países europeus tem estudado formas viáveis para tratar os diferentes tipos de efluentes, principalmente o doméstico, ganhando visibilidade a reutilização de águas cinzas. Este trabalho foi realizado nos Estados Unidos, em Macon - GA, e teve como objetivo criar dois grupos de filtros intermitentes de areia e analisar sua eficiência no tratamento de água cinza sintética, avaliando os parâmetros químicos de DBO e DQO, e partir dos resultados verificar a viabilidade para reuso urbano não potável e incentivando, através dos resultados, um tipo de estudo promissor para realização no Brasil. O estudo apresentou resultados satisfatórios quanto aos aspectos químicos analisados, atuando na redução da DBO e DQO com eficiência acima de $90 \%$ para o grupo 1 e acima de $80 \%$ para o grupo 2, além de ter apresentado filtros de efluente com valores médios de DBO aceitáveis, segundo a legislação prevista pela USEPA.

Palavras-chave: Sustentabilidade; Filtração intermitente; Tratamento de Água cinza; Parâmetros químicos

\section{Abstract}

Water is a renewable and limited resource, however its potability is an essential factor, since the increase of population in a disorderly way linked to the indiscriminate use of such a resource has posed a threat to the quality of it. In order to find simple, sustainable and low-cost solutions, several countries, such as the United States, Japan and some European countries, have been studying viable ways to treat different types of effluents, especially the domestic ones, gaining visibility for gray water reuse. This work was realized in the United States, Macon - GA, and aimed to create two groups of intermittent sand filters in order to analyze their efficiency in the treatment of synthetic gray water, evaluating the chemical parameters of BOD and COD, and from the results verify the feasibility for non-potable urban reuse and encouraging, through the results, a promising type of study to be carried out in Brazil. The study presented satisfactory results regarding the analyzed chemical aspects, acting in the reduction of BOD and COD with efficiency above $90 \%$ for group 1 and above $80 \%$ for group 2, besides having effluent filters with mean values of BOD accordance with the legislation envisaged by the USEPA.

Keywords: Sustainability; Intermittent filtration; Treatment grey water; Chemical parameters

Bacharel em Engenharia Ambiental e Energias Renováveis, Universidade Federal Rural da Amazônia, PA, Brasil - taisalcantara2@hotmail.com "Mestrando em Ciências Ambientais pelo Programa de Pós-Graduação em Ciências Ambientais do Instituo de Geociências. Universidade Federal do Pará, PA, Brasil - emersonrvs255@gmail.com

III Bacharel em Engenharia Ambiental. Instituto Federal Fluminense,RJ, Brasil - caio_cesar.barbosa@hotmail.com

Iv Bacharel em Engenharia Ambiental. Universidade Federal do Ceará, CE, Brasil - laryssa.bf@gmail.com

`Docente da Mercer University, Macon-GA, Geórgia, Estados Unidos da Améria - mccreanor_pt@mercer.edu

vı Doutorando em Ciências Ambientais, Programa de Pós-Graduação em Ciências Ambientais, Universidade Federal do Pará, PA, Brasil -

ivan.barbosa1212@gmail.com 


\section{Introdução}

A água é um recurso renovável e limitado, no entanto sua potabilidade constitui-se um fator imprescindível nos dias de hoje, visto que devido ao aumento da população de forma desordenada atrelado ao uso indiscriminado de tal recurso promoveu uma ameaça à qualidade da mesma. Desta forma, o reuso de águas residuais atrelado ao tratamento adequado é considerada uma ótima alternativa para a problemática vivida atualmente, contribuindo para a sustentabilidade do planeta, na redução de insumos e na conscientização da população referente a da reutilização de água.

O crescimento populacional não só influencia a demanda de água pelo consumo individual como também afeta, de forma indireta, a expansão das atividades industriais e agrícolas (CHIN, RODDICK e HARRIS, 2009). É importante ressaltar que o setor agrícola exerce o maior consumo de água doce do planeta, correspondendo a $70 \%$; seguido do consumo doméstico apresentando $23 \%$ e aumentando cerca de $4 \%$ ao ano desde 1990 e finalizando com o setor industrial que atende a 7\% (TERPSTRA, 1999).

Uma grande parcela da população brasileira sofre com a escassez hídrica em regiões urbanas, interferindo no crescimento econômico das mesmas, provocando o adiamento do seu progresso. Tal realidade é vivenciada por diversas cidades brasileiras, onde o abastecimento de água encontra-se ameaçado em quantidade, com relação as ocorrências do período de escassez de água, e em qualidade, em decorrência de modificações ocorridas na qualidade da água através da poluição (GONÇALVES, 2006).

O reuso de água auxilia na redução da demanda sobre os mananciais de água, devido a substituição da água potável por uma água apresentando qualidade inferior (RESOLUÇÃO N. 54 DE 28 DE NOVEMBRO DE 2005). Essa prática vem sendo utilizada em diversos países e se baseia no conceito da substituição de mananciais. Sendo assim, é possível poupar grandes volumes de água potável através do reuso quando se utiliza água de qualidade inferior, efluentes pós tratados, afim de atender as necessidades de água seguindo o padrão de potabilidade (CARVALHO et al., 2014).

A reciclagem de águas residuais e águas cinzas surgem como partes integrantes da gestão da demanda hídrica, promovendo a preservação da alta qualidade de água doce, bem como reduzindo poluentes no meio ambiente e os custos gerais de fornecimento. Este processo já é realidade em países como Estados Unidos, Japão e alguns países da Europa, sendo que estes apresentam legislação específica para o desenvolvimento da atividade além de obrigações de implantação de sistemas de tratamento e recirculação da água utilizada (MORELLI, 2005).

De acordo com a NBR 15.527, algumas das estratégias existentes para reuso são: aproveitamento de água pluvial, o reuso de águas cinzas e a instalação de componentes economizadores de água. (ABNT, 2007).

Atualmente existem diversas tecnologias empregadas ao tratamento de águas cinzas, tais como tanques sépticos, filtros de carvão ativado e filtros intermitentes de areia. De acordo com Allen, Christian-Smith e Palaniappan (2010), o filtro aeróbico com a utilização de areia é considerado uma das tecnologias mais comuns para o tratamento de água cinza, visto que tal metodologia fornece alta qualidade de efluentes com valores de DBO e sólidos suspensos totais (TSS) inferiores a $20 \mathrm{mg} \mathrm{L}^{-1}$. No Reino Unido a filtração em filtro de areia seguida por desinfecção é a técnica mais utilizada para tratamento de águas cinza residenciais (JEFFERSON et al., 1999). No Brasil, de acordo com a NBR 13.969, recomenda-se o filtro de areia quando se deseja um sistema de pós-tratamento simplificado (ABNT, 1997).

Desta forma, diante de toda essa conjuntura apresentada, o presente trabalho tem por objetivo o avaliar a eficiência de dois grupos de filtros intermitentes de areia empregados para o tratamento de água cinza sintética realizados no departamento de Engenharia, da Mercer University, Campus Macon - Geórgia (EUA), e desta forma apresentar o filtro que obteve resultados consideráveis para o tratamento do efluente analisando os níveis de Demanda Bioquímica de Oxigênio (DBO) e Demanda Química de Oxigênio (DQO).

\section{Material e Métodos}

\subsection{Informações preliminares}

As análises e testes realizados no presente estudo foram realizados no laboratório de Engenharia Ambiental, localizado no departamento de Engenharia da Mercer University, campus Macon, GA, Estados Unidos. O experimento contou com o auxílio e supervisão do Professor Dr. Philip T. McCreanor, (Departamento de Engenharia Ambiental da Mercer University).

A pesquisa teve como finalidade avaliar a eficiência de remoção de DBO e DQO de dois grupos de filtros intermitentes de areia, sendo o grupo 1 (um) formado por filtros de diferentes diâmetros (3", 4" e 6" - "lê-se polegadas) e mesma taxa de carregamento hidráulico (40,8 lpd $\mathrm{m}^{-2}$ - lê-se litros por dia por metros quadrados). Enquanto que, o grupo 2 (dois) era composto por filtros de mesmos diâmetros (4") e taxas de carregamento hidráulico diferentes $\left(24,5,36,7\right.$ e 48,9 $\left.\mathrm{lpd} \mathrm{m}^{-2}\right)$. No geral o projeto ocorreu durante um período de aproximadamente 40 semanas, sendo que os filtros de mesmos diâmetros iniciaram primeiro, visto que já haviam análises sendo realizadas anteriormente a este trabalho.

O trabalho procurou utilizar os filtros de forma análoga ao funcionamento de uma residência, sendo incluídos na pesquisa: um momento de pausa em que o sistema não apresentaria uso denominado como teste de férias, e uma ocasião em que os filtros seriam carregados com volumes acima do seu valor usual, denominado teste de eficiência. Para cada uma dessas etapas utilizou-se um período de 9 dias.

\subsection{Preparo da água cinza sintética}

A produção da água cinza sintética, também denominada afluente neste estudo, foi utilizada com o intuito de avaliar a eficiência de remoção da DBO e DQO através da utilização de filtros intermitentes de areia. Para a 
produção da água foram empregues três tipos de componentes: solução concentrada, água da torneira e efluente secundário, sendo feita de acordo com Regulamentação NSF 350 para sistemas de tratamento de efluente (BRUURSEMA, 2011). A Tabela 1, a seguir, apresenta os itens utilizados para fabricação da solução estoque.

Tabela 1 - Componentes da solução concentrada

\begin{tabular}{lc}
\hline \multicolumn{1}{c}{ Componentes } & $\begin{array}{c}\text { NSF/ANSI } \\
\text { Quantidade/100L }\end{array}$ \\
\hline Sabonete corporal & $30 \mathrm{~g}$ \\
Creme dental & $3 \mathrm{~g}$ \\
Desodorante & $2 \mathrm{~g}$ \\
Shampoo & $19 \mathrm{~g}$ \\
Condicionador & $21 \mathrm{~g}$ \\
Ácido lático & $3 \mathrm{~g}$ \\
Limpador de banheiro & $10 \mathrm{~g}$ \\
Sabonete líquido & $23 \mathrm{~g}$ \\
para mãos & $40 \mathrm{~mL}$ \\
Detergente líquido & $21 \mathrm{~mL}$ \\
para lavanderia & $4 \mathrm{~g}$ \\
Amaciante líquido & $2 \mathrm{~g}$ \\
Sulfato de sódio & $4 \mathrm{~g}$ \\
Bicarbonato de sódio & \\
Fosfato dissódico &
\end{tabular}

A fabricação da água cinza sintética ocorreu de forma diária, seguindo os componentes presentes na Tabela 2, perfazendo um total de 2,5 litros de água cinza sintética (afluente) ao dia, sendo a mesma mantida refrigerada durante o período de avaliação. Com relação ao efluente secundário, este foi obtido da Lower Poplar Wastewater Treatment Plant localizada em Macon, Geórgia.

Tabela 2 - Volumes de diluição

\begin{tabular}{lc}
\hline \multicolumn{2}{c}{ Volumes de diluição } \\
\hline Solução concentrada & $133 \mathrm{~mL}$ \\
Água da torneira & $2317 \mathrm{~mL}$ \\
Efluente secundário & $50 \mathrm{~mL}$ \\
\hline
\end{tabular}

\subsection{Confecção dos filtros}

Com o intuito de proporcionar um método de tratamento apresentando baixo custo, para a construção dos filtros intermitentes de areia foram utilizados materiais acessíveis como tubos de PVC, areia e cascalho. Os filtros apresentavam três tipos de diâmetros, 3,4 e 6 polegadas. A parte interna dos filtros era composta por 7,62 $\mathrm{cm}$ de cascalho, $76,2 \mathrm{~cm}$ de areia (número 20) e 5,08 $\mathrm{cm}$ de cascalho. Vale ressaltar que os dois grupos de filtros foram construídos utilizando o mesmo design como pode ser observado pelo desenho seccional e os filtros utilizados no estudo, como demonstrado na Figura 1 abaixo.

Figura 1- Desenho seccional dos filtros ${ }^{(a)}$, filtros do grupo $1^{(b)}$ e filtros do grupo $2^{(c)}$, respectivamente

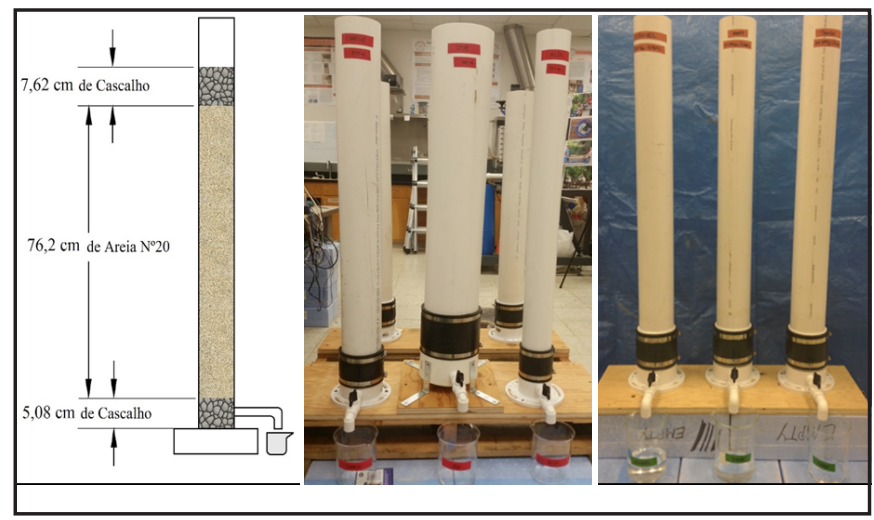

\subsection{Funcionamento dos filtros}

Para o grupo 1, com diâmetros diferentes, eram utilizados os seguintes volumes de água cinza sintética/afluente para carrega-los: 195, 335 e $760 \mathrm{~mL}$ para os filtros de 3, 4 e 6 polegadas de diâmetro, respectivamente. O grupo 2, com diâmetro de 4 polegadas, recebiam 205, 307 e $409 \mathrm{~mL}$ de água cinza sintética para os filtros de $24,5,36,7$ e $48,9 \mathrm{lpd} \mathrm{m}^{-2}$, respectivamente. A Tabela 3 apresenta cada tipo de filtro mencionado acima.

O desempenho dos filtros foi avaliado com base no monitoramento dos afluentes e efluentes da DQO e DBO.

Tabela 3 - Grupos de filtros intermitentes

\begin{tabular}{|c|c|c|c|}
\hline Grupos & $\begin{array}{c}\text { Diâmetros } \\
\text { (polegadas) }\end{array}$ & 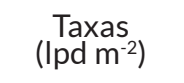 & $\begin{array}{l}\text { Afluente } \\
\text { (mL) }\end{array}$ \\
\hline \multirow{3}{*}{1} & 3" & $40,8 \mathrm{lpd} \mathrm{m}^{-2}$ & 195 \\
\hline & $4 "$ & $40,81 \mathrm{pd} \mathrm{m}{ }^{-2}$ & 335 \\
\hline & $6 "$ & 40,8 lpd m-2 & 760 \\
\hline \multirow{3}{*}{2} & $4 "$ & $24,5 \mathrm{lpd} \mathrm{m}^{-2}$ & 205 \\
\hline & $4 "$ & $36,7 \mathrm{lpd} \mathrm{m^{-2 }}$ & 307 \\
\hline & $4^{\prime \prime}$ & $48,91 \mathrm{pd} \mathrm{m}{ }^{-2}$ & 409 \\
\hline
\end{tabular}

O teste de DQO, utilizado para medir a quantidade de produtos químicos presentes na água que podem ser oxidados, foi realizado a cada três dias, afim de analisar o momento em que os filtros atingissem a estabilidade. Já o teste da DBO foi utilizado para verificar a quantidade de matéria orgânica disponível para a oxidação bacteriana. Em outras palavras, é uma medida da quantidade de alimento disponível para as bactérias consumirem. O resultado da $\mathrm{DQO}$ será maior que o resultado da $\mathrm{DBO}$, na maioria das vezes, e é utilizado como guia para a diluição da DBO.

\subsection{Determinação da DQO}

A análise de DQO foi realizada com o equipamento Hach modelo DR 2800, e efetuada a cada três dias. Através dos resultados de tais analises, foi calculada a taxa de diluição necessária para a execução da DBO5. Para 
o procedimento de DQO, foram utilizados 2 frascos de branco (contendo água deionizada) e 2 frascos para análise de afluentes com medição de grande alcance; e 6 frascos para efluentes dos filtros, com medição de alcance ultra-baixo. O frasco em branco foi carregado com $2 \mathrm{~mL}$ de água deionizada. Posterior a preparação dos frascos, os mesmos eram dispostos no Hach digestor de DQO, onde permaneciam por 2 horas. Após este período, os frascos eram limpos usando lenços Kim Wipe e após a limpeza era realizada a leitura através do equipamento Hach DR 2800. Por fim, cada valor de DQO obtido era armazenado em uma planilha no Excel para determinar o novo volume de DBO5 necessário para cada garrafa.

\subsection{Determinação da DBO}

Para este experimento foi medido $\mathrm{DBO}$ e $\mathrm{DBO}_{5}$ das amostras dos dois tipos de filtros. Durante um período de 5 dias as mesmas eram armazenadas à $20^{\circ} \mathrm{C}$. A diferença entre as concentrações de oxigênio no início e no fim do período de incubação corresponde a concentração DBO, em $\mathrm{mg} \mathrm{L}^{-1}$.

Para o experimento, foram preparadas 24 garrafas por dia, que consistiam em três garrafas para o afluente, três para amostra de branco e três amostras de cada um dos seis filtros intermitentes de areia. A garrafa em branco consistia de uma mistura de água destilada e BOD Nutrient Buffer Pillows, sendo este reagente utilizado para preparar a água de diluição da $\mathrm{DBO}_{5}$. Já a garrafa de afluente continha determinada quantidade de água cinza sintética, e seu volume restante era preenchido com água de diluição.

As garrafas correspondentes às amostras continham uma certa quantidade de efluente de cada filtro, sendo o valor calculado através da análise de DQO, e o volume restante também era preenchido com água de diluição.

Para realizar a medição do OD inicial foi utilizado o equipamento Hach modelo HQ440d. Após a medição os valores eram anotados e salvos em uma planilha do Excel, em seguida, os frascos eram rotulados e armazenados em uma incubadora por cinco dias a uma temperatura de $20^{\circ} \mathrm{C}$.

O cálculo para o volume utilizado em cada filtro foi baseado no pressuposto de águas residuais. Assim, para o cálculo do volume de água cinza sintética utilizado para cada filtro, foi utilizada a equação 1, e para o cálculo dos valores de DBO5, utilizou-se a equação 2 .

$$
\begin{aligned}
& D \mathrm{DO}_{5}=\frac{2}{3} X \mathrm{XQO} \\
& \frac{(\text { ODInicial }-O D 5)}{(\text { Volume da amostra }) /(\text { Volume da garrafa })}
\end{aligned}
$$

Sendo que o ODinicial é o oxigênio dissolvido antes da incubação (mg L ${ }^{-1}$ ), e ODfinal o oxigênio dissolvido após incubação de cinco dias $\left(\mathrm{mg} \mathrm{L}^{-1}\right)$ e v é o volume de amostra.

Os resultados obtidos nas análises de DQO e DBO e as taxas de remoção de eficiência foram submetidos a análise estatística de Tukey a $5 \%$ de probabilidade, com auxílio do software Minitab ${ }^{\circledR}$ Statistical Software.

\section{Resultados e Discussões}

\subsection{Filtros intermitentes de diâmetros diferentes}

Para a análise estatística foram levadas em consideração os resultados de $\mathrm{DBO}$ e $\mathrm{DQO}$ e suas respectivas taxas de eficiência de remoção da DBO e DQO do grupo 1, de 3, 4 e 6 polegadas de diâmetros e submetidas a mesma taxa de carregamento hidráulico $\left(40,8 \mathrm{lpd} \mathrm{m}^{-2}\right)$, como mostra a Tabela 4 , a seguir.

Os dados apresentados na Tabela 5 demonstram que os três filtros apresentaram redução nos parâmetros de DBO e DQO. Quanto a eficiência de remoção os resultados foram sempre superiores à $80 \%$ tanto para DBO quanto DQO.

Quando submetidos os dados à análise estatística de Tukey $(\mathrm{p}<0,05)$ (Tabela 5), é possível verificar que a eficiência de remoção da DBO e DQO, para os três filtros, não apresentam diferenças significativas entre si, visto que compartilham a mesma letra. Entretanto, cabe salientar que o filtro com diâmetro de 3 polegadas apresentou média semelhante à amostra de branco na análise de DBO. Não obstante, levando em consideração que o afluente foi o que apresentou médias de DBO e DQO significativamente maiores do que os filtros avaliados, independente do tipo de filtro utilizado, todos eles reduziram os valores de DBO e DQO, e apresentam-se como ótima alternativa para sua finalidade. Todos valores de DBO do grupo 1 encontrados no experimento, após a utilização dos filtros intermitentes, se apresentam menores que 20 $\mathrm{mg} \mathrm{L}^{-1}$, como comprovado por Dultra (2017) que em seu estudo com filtros intermitentes de areia para efluente obteve DBO abaixo de $20 \mathrm{mg} \mathrm{L}^{-1}$.

As Figuras 2 e 3 demonstram o comportamento da eficiência de remoção da DBO e DQO apresentada pelos filtros no período avaliado.

Com base na Figura 2, observa-se que os filtros começam a ganhar estabilidade após 40 dias de experimento, demonstrando que as eficiências de remoção para os três filtros evidenciam uma tendência crescente. O gráfico também demonstra que o filtro de 3 polegadas (linha azul) atinge níveis de eficiência mais altos num período de tempo menor quando comparado aos filtros de 4 e 6 polegadas (linhas laranja e cinza, respectivamente). Ao mesmo tempo, pode-se afirmar que após o período de 60 dias, os três filtros apresentaram eficiências acima de $90 \%$. Sodamade, Longe e Sangodoyin (2015) relataram em seu estudo remoções de DBO de 90 a 95\%, utilizando filtros de areia.

A fim de representar um sistema análogo ao uso residencial, foram incluídas mais 2 etapas no período experimental, sendo o teste de férias e teste de eficiência. Estes executados por um período de 9 dias cada um. O primeiro representou a ausência do uso do sistema, enquanto que o segundo representou uma utilização do sistema acima do usual.

Relacionado ao teste de férias, é possível afirmar que após esse período os filtros não apresentaram 
Tabela 4 - Teste de Tukey à 5\%, para leitura dos parâmetros avaliados (DBO, DQO e taxa de eficiência de remoção da DBO e DQO), no tratamento de água cinza sintética com a utilização de filtros intermitentes de areia

\begin{tabular}{|c|c|c|c|c|c|}
\hline & & DBO & DQO & $\begin{array}{c}\text { Taxa de } \\
\text { eficiência de } \\
\text { remoção da DBO }\end{array}$ & $\begin{array}{c}\text { Taxa de eficiência } \\
\text { de remoçẫo da } \\
\text { DQO }\end{array}$ \\
\hline \multirow{4}{*}{ BRANCO } & Média & $0,35 \mathrm{C}$ & \multirow{4}{*}{ - } & \multirow{4}{*}{ - } & \multirow{4}{*}{-} \\
\hline & Desvio padrão & 0,77 & & & \\
\hline & Máximo & 5,12 & & & \\
\hline & Mínimo & $-4,40$ & & & \\
\hline \multirow{4}{*}{ AFLUENTE } & Média & $152,71 \mathrm{~A}$ & $307,5 \mathrm{~A}$ & \multirow{4}{*}{ - } & \multirow{4}{*}{-} \\
\hline & Desvio padrão & 61,12 & 99,9 & & \\
\hline & Máximo & 157,48 & 327,4 & & \\
\hline & Mínimo & 147,95 & 287,7 & & \\
\hline \multirow{4}{*}{$3^{\prime \prime}$} & Média & 8,98 BC & $32,23 \mathrm{~B}$ & $93,23 \mathrm{~A}$ & $87,08 \mathrm{~A}$ \\
\hline & Desvio padrão & 13,83 & 38,0 & 11,22 & 16,53 \\
\hline & Máximo & 13,74 & 52,06 & 95,56 & 93,32 \\
\hline & Mínimo & 4,22 & 12,41 & 90,90 & 80,83 \\
\hline \multirow{4}{*}{$4 "$} & Média & 12,79 B & $39,75 \mathrm{~B}$ & $90,26 \mathrm{~A}$ & $83,95 \mathrm{~A}$ \\
\hline & Desvio padrão & 22,60 & 53,71 & 17,99 & 22,83 \\
\hline & Máximo & 17,55 & 59,58 & 92,59 & 90,20 \\
\hline & Mínimo & 8,03 & 19,93 & 87,93 & 77,71 \\
\hline \multirow{4}{*}{ 6" } & Média & 12,46 B & $39,49 \mathrm{~B}$ & $90,37 \mathrm{~A}$ & $83,99 \mathrm{~A}$ \\
\hline & Desvio padrão & 19,00 & 47,12 & 15,56 & 20,71 \\
\hline & Máximo & 17,22 & 59,31 & 92,70 & 90,23 \\
\hline & Mínimo & 7,69 & 19,66 & 88,04 & 77,75 \\
\hline
\end{tabular}

Médias seguidas pela mesma letra, em uma coluna, não apresentam diferença significativa entre si, segundo teste de Tukey à 5\%.

Figura 2 - Gráfico de eficiência de remoção da DBO para filtros com diferentes diâmetros

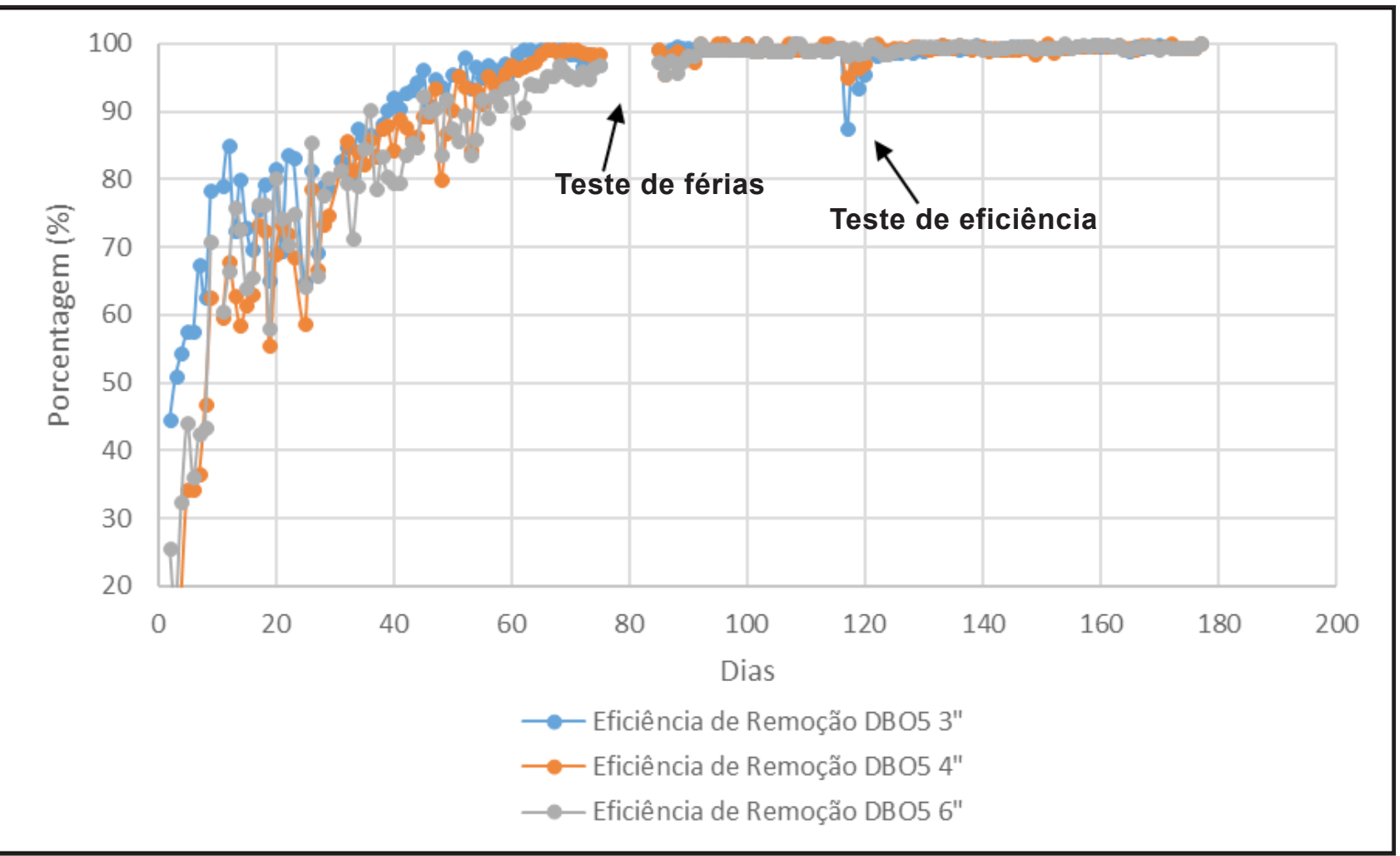


Figura 3 - Gráfico de eficiência de remoção de DQO para filtros com diferentes diâmetros

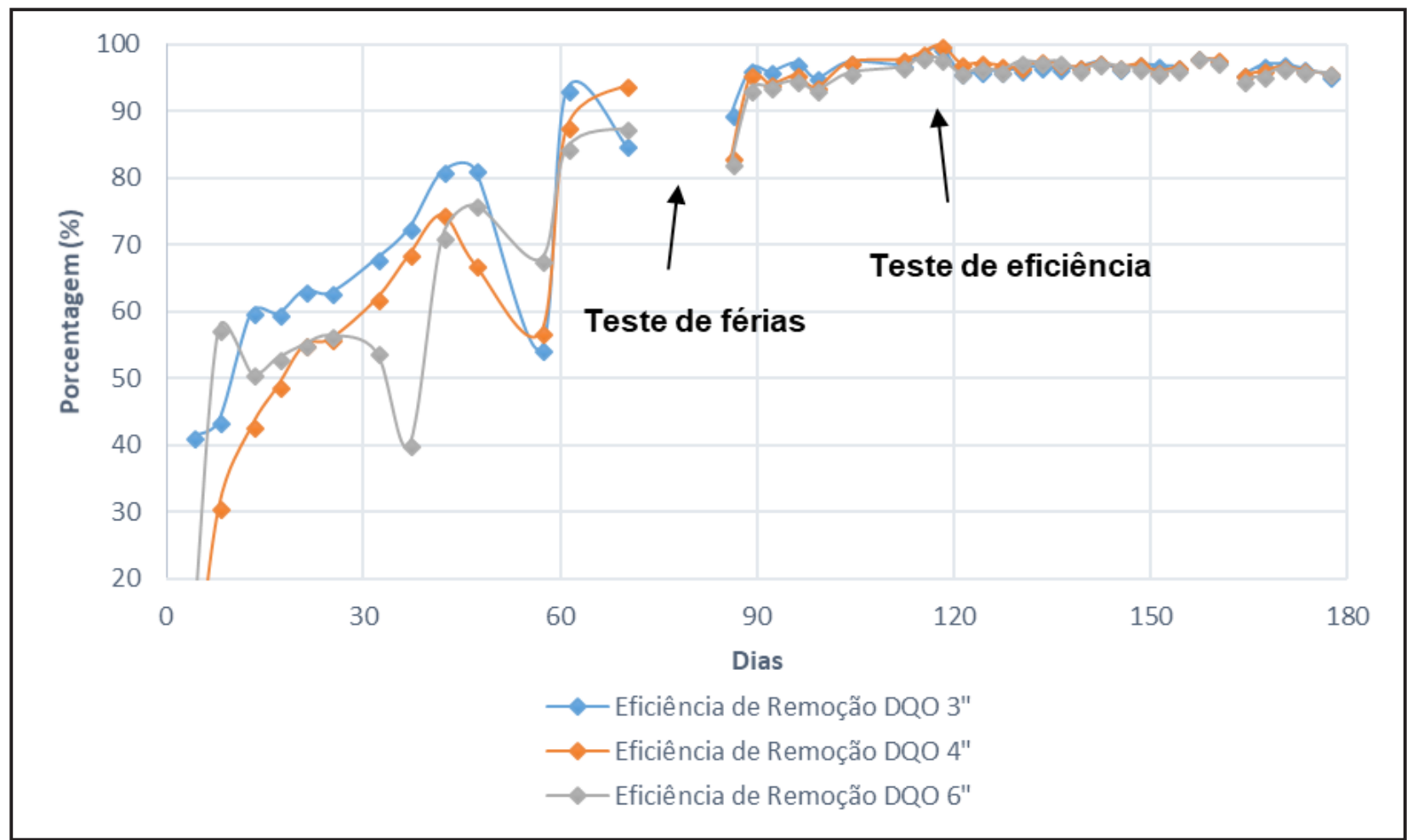

nenhuma mudança significativa no que diz respeito a eficiência de remoção da DBO. Já para o teste de eficiência, os filtros apresentaram uma queda inicial quando comparado aos dias regulares de estudo, porém em seguida mantiveram a estabilidade atingida ao longo do estudo. Cabe destacar que o filtro de 3 polegadas foi o único que demonstrou uma queda abaixo de $90 \%$ no teste de férias, quando comparado aos filtros de 4 e 6 polegadas.

De acordo com a Figura 3, observa-se que os filtros atingiram a estabilidade após aproximadamente 90 dias de experimento para a eficiência de remoção da DQO. Demonstra ainda que as eficiências de remoção para os três filtros evidenciaram uma tendência crescente. Ao mesmo tempo, comprova-se ainda que após esse período, os três filtros apresentaram eficiências acima de $90 \%$, corroborando com os resultados encontrados por Sabbah et al. (2003). Estes autores identificaram remoção consistente de $70-90 \%$ utilizando filtros intermitentes de areia para tratamento de efluentes.

Para a eficiência de remoção da DQO (Figura 3), o teste de férias mostrou que após esse período, os filtros demonstraram uma redução inicial com relação à eficiência. Sendo que o filtro de 6 polegadas (linha cinza) apresentou eficiência abaixo de $90 \%$ quando comparado aos filtros de 3 e 4 polegadas (linha azul e laranja, respectivamente). Já com relação ao teste de eficiência, os filtros demonstraram eficiências maiores neste período quando comparado aos dias regulares de estudo. Todavia, após este momento, os resultados prosseguiram com médias elevadas de eficiência.

\subsection{Filtros intermitentes de diâmetros iguais}

A análise estatística dos resultados de DBO e DQO, bem como suas respectivas taxas de eficiência de remoção da $\mathrm{DBO}$ e DQO, também foram realizadas para o grupo 2 de filtros de mesmo diâmetro e taxas de carregamento hidráulico diferentes $\left(24,5,36,7\right.$ e $\left.48,9 \mathrm{lpd} / \mathrm{m}^{2}\right)$. A Tabela 5 a seguir apresenta os valores encontrados.

Analisando os valores da Tabela 5 é possível inferir que a utilização de filtros intermitentes com taxas de carregamento hidráulico distintas também obteve redução da DBO. Logo, o tratamento se mostra eficiente visto que apresentou resultados consideráveis de redução do parâmetro avaliado.

Após submeter os dados à análise estatística de Tukey $(\mathrm{p}<0,05)$, mencionados na Tabela 5 , é possível afirmar que para o parâmetro de DBO, o filtro com taxa de 48,9 lpd $\mathrm{m}^{-2}$ apresentou resultados significativamente diferentes quando comparados aos filtros de 24,5 e $36,7 \mathrm{lpd} \mathrm{m}^{-2}$. Além disso, os filtros com taxas de 24,5 e $36,7 \mathrm{lpd} \mathrm{m}^{-2}$ demonstraram ainda semelhanças à amostra de branco.

No tocante à análise de DQO, os três filtros apresentam-se semelhantes entre si, não demonstrando nenhuma diferença significativa.

Com referência a análise de $\mathrm{DBO}$ os três filtros apresentaram médias menores que $10 \mathrm{mg} \mathrm{L}^{-1}$, o que de acordo com os padrões da USEPA (2012) indicam a viabilidade de reuso para o parâmetro analisado.

Com relação às análises de eficiência de remoção da DBO, os três filtros apresentaram comportamento semelhante, exibindo eficiência de remoção média acima de $95 \%$. Do mesmo modo, para a análise de eficiência de remoção de DQO, os três filtros apresentaram efi- 
Tabela 5 - Teste de Tukey à 5\%, para leitura dos parâmetros avaliados (DBO, DQO e taxa de eficiência de remoção da DBO e DQO), no tratamento de água cinza sintética com a utilização de filtros intermitentes de areia

\begin{tabular}{|c|c|c|c|c|c|}
\hline & & DBO & DQO & $\begin{array}{c}\text { Taxa de } \\
\text { eficiência de } \\
\text { remoção DBO }\end{array}$ & $\begin{array}{l}\text { Taxa de eficiência } \\
\text { de remoção DQO }\end{array}$ \\
\hline BRANCO & $\begin{array}{l}\text { Média } \\
\text { Desvio padrão } \\
\text { Máximo } \\
\text { Mínimo }\end{array}$ & $\begin{array}{c}0,37 \mathrm{C} \\
0,67 \\
3,66 \\
-2,90\end{array}$ & - & - & - \\
\hline AFLUENTE & $\begin{array}{l}\text { Média } \\
\text { Desvio padrão } \\
\text { Máximo } \\
\text { Mínimo }\end{array}$ & $\begin{array}{c}146,33 \mathrm{~A} \\
52,78 \\
149,62 \\
143,04\end{array}$ & $\begin{array}{c}286,05 \mathrm{~A} \\
85,9 \\
298,0 \\
274,9\end{array}$ & - & - \\
\hline $24,5 \mathrm{lpd} \mathrm{m-2}$ & $\begin{array}{l}\text { Média } \\
\text { Desvio padrão } \\
\text { Máximo } \\
\text { Mínimo }\end{array}$ & $\begin{array}{c}4,96 \mathrm{BC} \\
11,64 \\
8,26 \\
1,67\end{array}$ & $\begin{array}{c}18,05 \text { B } \\
20,02 \\
29,06 \\
6,51\end{array}$ & $\begin{array}{c}96,42 \mathrm{~A} \\
10,03 \\
97,71 \\
95,13\end{array}$ & $\begin{array}{c}92,98 \mathrm{~A} \\
8,25 \\
95,22 \\
90,74\end{array}$ \\
\hline $36,7 \mathrm{lpd} \mathrm{m-2}$ & $\begin{array}{l}\text { Média } \\
\text { Desvio padrão } \\
\text { Máximo } \\
\text { Mínimo }\end{array}$ & $\begin{array}{c}5,54 \mathrm{BC} \\
13,33 \\
8,82 \\
2,25\end{array}$ & $\begin{array}{c}20,35 \mathrm{~B} \\
21,70 \\
31,85 \\
8,76\end{array}$ & $\begin{array}{c}96,14 \mathrm{~A} \\
10,34 \\
97,43 \\
94,86\end{array}$ & $\begin{array}{c}92,08 \mathrm{~A} \\
9,10 \\
94,32 \\
89,84\end{array}$ \\
\hline 48,9 lpd m-2 & $\begin{array}{l}\text { Média } \\
\text { Desvio padrão } \\
\text { Máximo } \\
\text { Mínimo }\end{array}$ & $\begin{array}{c}7,50 \mathrm{~B} \\
19,81 \\
10,79 \\
4,21\end{array}$ & $\begin{array}{c}24,74 \mathrm{~B} \\
22,85 \\
36,38 \\
13,10\end{array}$ & $\begin{array}{c}95,12 \mathrm{~A} \\
10,67 \\
96,41 \\
93,83\end{array}$ & $\begin{array}{c}90,34 \mathrm{~A} \\
9,82 \\
92,59 \\
88,08\end{array}$ \\
\hline
\end{tabular}

Médias seguidas pela mesma letra, em uma coluna, não apresentam diferença significativa entre si, segundo teste de Tukey à 5\%.

ciência semelhante entre si, com remoção média acima 90\%. Segundo Boller (1993), filtros de areia apresentam melhor eficiência quando apresentam menores taxas de carregamento hidráulica, porque as taxas menores são cruciais para reter partículas que são gravitacionalmente depositadas na superfície do meio.

As Figuras 4 e 5 demonstram o comportamento da eficiência de remoção da DBO e DQO apresentada pelos filtros no período avaliado.

A Figura 4 demonstra que, após quase 70 dias do experimento, é possível afirmar que os três filtros demonstram uma tendência de aumento em sua eficiência, manifestando um ciclo estável. Também é possível concluir que o filtro de $24,5 \mathrm{lpd} \mathrm{m}^{-2}$ (linha cinza) apresentou percentuais de remoção maiores num curto período de tempo quando comparado aos filtros de 36,7 e $48,9 \mathrm{lpd} \mathrm{m}^{-2}$ (linha laranja e azul, respectivamente). Não obstante, todos os filtros demonstraram expressiva eficiência de remoção da DBO e maiores que $90 \%$, depois de alcançada a estabilidade.

No que tange o teste de férias, para a eficiência de remoção da DBO, após o período de descanso apenas o filtro de $48,9 \mathrm{lpd} \mathrm{m}^{-2}$ (linha azul) apresentou uma redução. No entanto, esse valor não chega a ser significativo visto que o filtro apresenta remoção de $95 \%$ após esse período. Já para o teste de eficiência, os três filtros apresentaram uma redução na eficiência nos primeiros dias de análise. Contudo, observa-se que o filtro de taxa $24,5 \mathrm{lpd} \mathrm{m}^{-2}$ (linha cinza) foi único a apresentar percentual menor que $90 \%$ nesse período. Ainda assim, ao final desta etapa os três filtros apresentaram médias com percentual acima de $90 \%$.

A análise da Figura 5 permite afirmar que para a eficiência de remoção da DQO, para os três filtros apresentaram certa estabilidade após aproximadamente 100 dias de experimento, demonstrando uma tendência crescente quanto aos percentuais de remoção.

É valido observar que, mais uma vez o filtro de $24,5 \mathrm{lpd}$ $\mathrm{m}^{-2}$ (linha cinza) atinge o momento estável num período de tempo menor quando comparado aos filtros de 36,7 e 48,9 lpd m $\mathrm{m}^{-2}$ (linha laranja e cinza, respectivamente). Contudo, após a estabilidade os três filtros apresentam algumas variações, porém expressivas eficiências de remoção, acima de $90 \%$ até o fim do estudo.

A respeito do teste de férias, é possível afirmar que o filtro de 48,9 $\mathrm{lpd} \mathrm{m}^{-2}$ (linha azul) foi o único que denotou uma redução menor que $90 \%$ após esse período de descanso. No entanto, nos dias posteriores os três filtros apresentaram funcionamento estável e eficiência de remoção com percentuais acima de $90 \%$. Já para o teste de eficiência, ambos os filtros demonstraram eficiências mais elevadas que os dias regulares, e ao final do teste os três filtros sofreram redução em sua eficiência, porém não relevante, visto que aprestaram percentuais maiores que $90 \%$. 
Figura 4 - Gráfico de eficiência de remoção de DBO para filtros com mesmos diâmetros e taxas de carregamento hidráulico diferentes

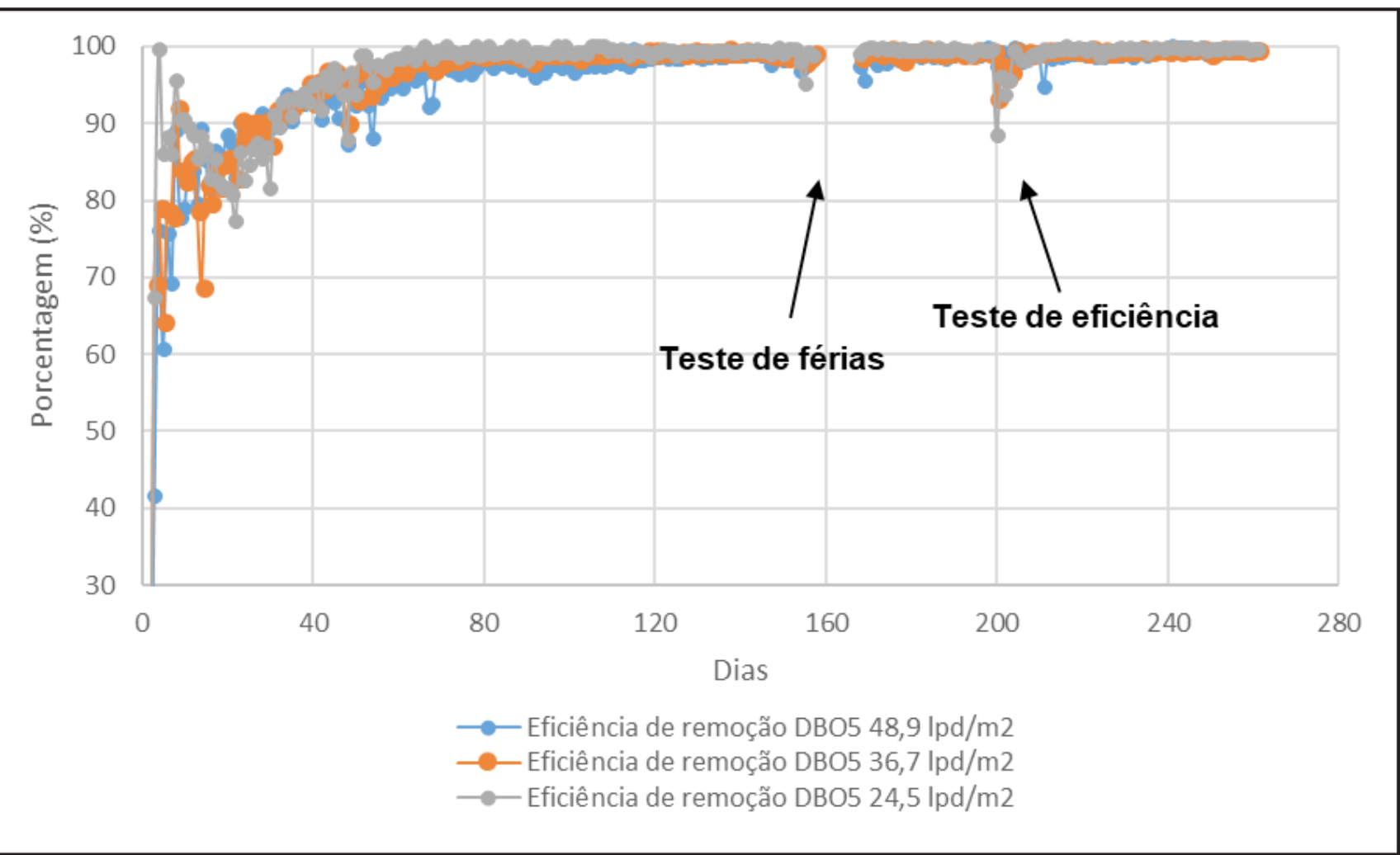

Figura 5 - Gráfico de eficiência de remoção de DQO para filtros com mesmos diâmetros e taxas de carregamento hidráulico diferentes

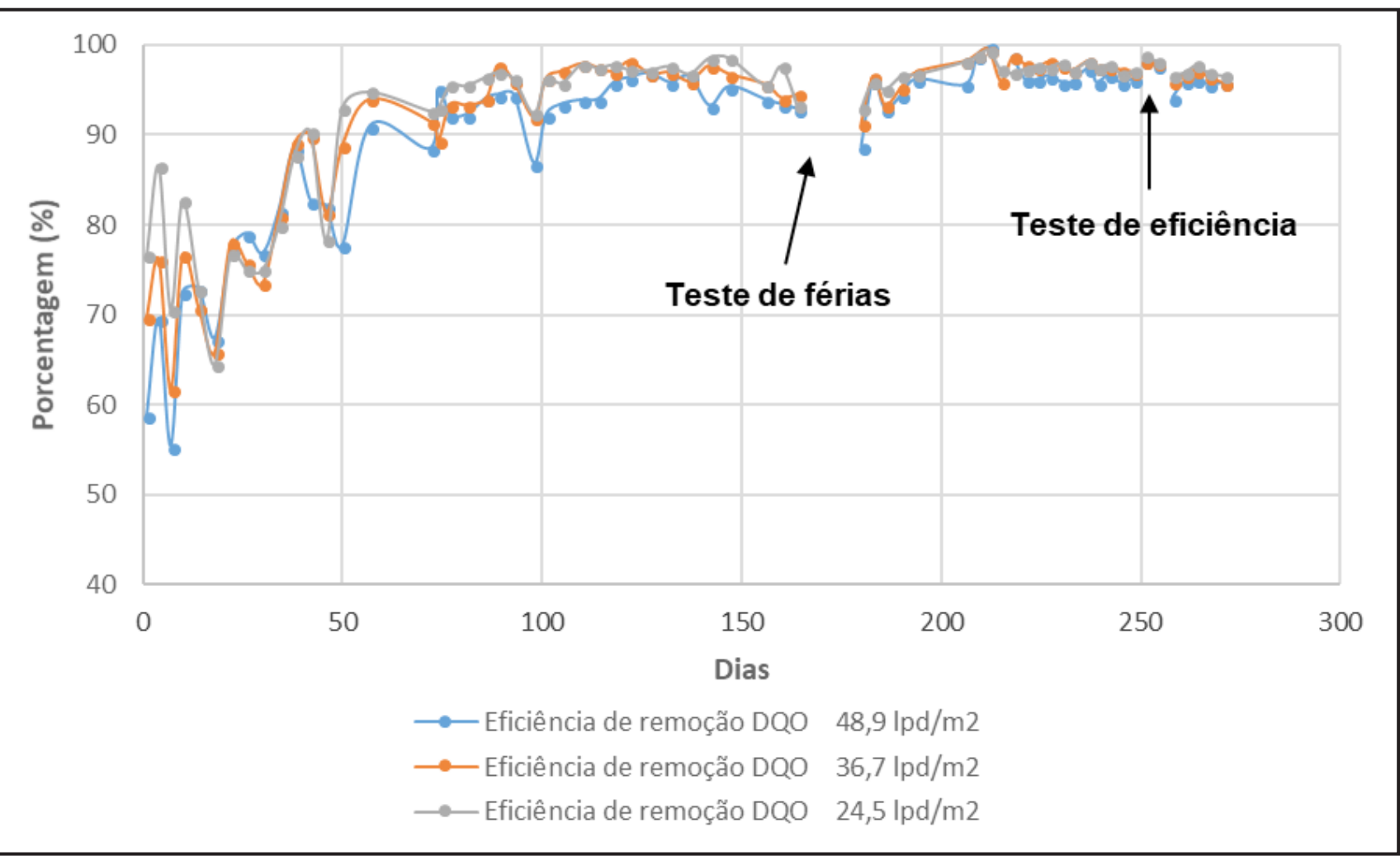




\subsection{Análise estatística entre os dois tipos de filtros}

A Tabela 6 abaixo apresenta comparativamente as médias encontradas para os dois grupos de filtros intermitentes de areia, levando em consideração as variáveis de $\mathrm{DBO}, \mathrm{DQO}$ e taxa de eficiência de remoção da $\mathrm{DBO}$ e DQO.

Para a análise de DBO percebe-se que os filtros de 4 e 6 polegadas demostraram ser significativamente diferentes quando comparados aos filtros de 3 polegadas e aos filtros do grupo 2. Entretanto, os filtros do grupo $2 \mathrm{e}$ o de 3 polegadas (do grupo 1) demonstraram semelhança em relação à amostra de branco.

Ao avaliar o parâmetro DQO os resultados indicam que todos os grupos de filtros obtiveram resultados semelhantes, sem nenhuma diferença significativa entre si.

A respeito da taxa de eficiência de remoção da $\mathrm{DBO}$, a Tabela 6 indica que o filtro de 3 polegadas é o único que possui semelhanças com os filtros do grupo 1 e 2 . Demonstra ainda que os filtros com diâmetros de $4 \mathrm{e}$ 6 polegadas são significativamente diferentes quando comparados aos filtros do grupo 2 e o de 3 polegadas. Já o grupo 2 são significativamente diferentes quando comparados aos filtros de 4 e 6 polegadas.

Com referência à taxa de eficiência de remoção da DQO é possível verificar que novamente o filtro de 3 polegadas apresenta semelhança estatística quando comparado aos filtros de 4 e 6 polegadas, apresentando ainda semelhanças com o grupo 2. Já os filtros de 4 e 6 polegadas apresentam diferenças significativas em relação ao filtro de 3 polegadas e ao grupo 2 . Os filtros de 3 polegadas, 36,7 e 48,9 lpd m-2 são semelhantes entre si, enquanto que o filtro de $24,5 \mathrm{lpd} \mathrm{m}-2$ é significativamente diferente do grupo 2 e dos filtros de 4 e 6 polegadas.

O grupo 1 apresentou valores de eficiência de remoção para DBO acima de $90 \%$, já para eficiência de remoção da
DQO os filtros apresentaram eficiência média acima de $80 \%$. Tais análises demonstram que o diâmetro dos filtros não é considerado um fator significativo para a questão do tratamento, visto que os três filtros apresentaram eficiências semelhantes. No entanto, cabe ressaltar que para o parâmetro de DBO o filtro de 3 polegadas apresentou semelhanças com amostra de branco. Além disso, a partir da média de DBO também se pode inferir que o mesmo filtro se apresenta de acordo com os padrões de reutilização, já que apresenta média de aproximadamente $9 \mathrm{mg} \mathrm{L}-1$. Segundo o padrão estabelecido pela USEPA (2012), o limite máximo é de $10 \mathrm{mg}$ L-1. Já os filtros de $4 \mathrm{e}$ 6 polegadas, apresentaram médias de aproximadamente $13 \mathrm{mg} \mathrm{L}-1$, sendo inviáveis para reutilização segundo o padrão de reuso para $\mathrm{DBO}$.

O grupo 2 apresentou menores médias e melhores resultados de eficiência quando comparados com o grupo 1 de filtros. As análises demonstraram que os filtros de 24,5 e 36,7 lpd m-2 apresentaram semelhança com a amostra de branco, o que indica que os filtros apresentam tratamento melhor quando comparados ao filtro de $48,9 \mathrm{lpd} \mathrm{m-2}$. Os dados também permitem inferir que as diferentes taxas de carregamento foram fatores determinante na eficiência de remoção dos parâmetros de $\mathrm{DBO}$ e DQO. Cabe ainda ressaltar que para o grupo 2 de filtros, tanto a eficiência de remoção da DBO quanto DQO obtiveram percentuais médios acima de $90 \%$. Segundo a média de DBO também se pode concluir que os filtros de 24,5, 36,7 e 48,9 lpd m-2 apresentam-se de acordo com os padrões de reutilização, pois possuem médias de aproximadamente 5,5 e $8 \mathrm{mg} \mathrm{L}-1$ de $\mathrm{DBO} 5$ em conformidade com o padrão USEPA (2012).

Fica evidente diante dos dados apresentados que o grupo 2, apesar de apresentar eficiência semelhante ao grupo 1, possui eficiências de remoção mais altas para os parâmetros de DBO e DQO.

Tabela 6 - Teste de Tukey à 5\%, analisando as variáveis DBO, DQO e taxa de eficiência de remoção da DBO e DQO entre os dois tipos de filtros intermitentes de areia

\begin{tabular}{|c|c|c|c|c|}
\hline & DBO & DQO & $\begin{array}{l}\text { Taxa de eficiência de } \\
\text { remoção da DBO }\end{array}$ & $\begin{array}{c}\text { Taxa de eficiência de } \\
\text { remoção da DQO }\end{array}$ \\
\hline BRANCO & C & - & - & - \\
\hline AFLUENTE & A & $A$ & - & - \\
\hline $3 "$ & $\mathrm{BC}$ & B & $A B$ & $A B$ \\
\hline $4^{\prime \prime}$ & B & B & B & B \\
\hline $6 "$ & B & B & B & B \\
\hline $24,5 \mathrm{lpd} \mathrm{m}{ }^{-2}$ & $\mathrm{BC}$ & B & A & A \\
\hline $36,7 \mathrm{lpd} \mathrm{m} \mathrm{m}^{-2}$ & $\mathrm{BC}$ & B & A & $A B$ \\
\hline $48,91 \mathrm{pd} \mathrm{m}{ }^{-2}$ & $\mathrm{BC}$ & B & $A$ & $A B$ \\
\hline
\end{tabular}




\section{Conclusões}

Este estudo visou à avaliação de duas propriedades dos filtros intermitentes de areia no tratamento de águas cinzas sintéticas: remoção de DBO e DQO. A partir do levantado, pôde-se constatar que:

(I) A redução da concentração de DBO e DQO ocorreu de forma considerável;

(II) Os diâmetros dos filtros de areia não se apresentam significativos na eficiência de remoção;

(III) A taxa de carregamento hidráulica demonstrou ser um fator determinante para este trabalho, pois comprova remoção de eficiência da $\mathrm{DBO}$ e DQO acima de $90 \%$ para os três filtros do grupo 2 ;

(IV) Não foram identificados problemas com relação à entupimento para nenhum dos grupos de filtros analisados;

(V) Apenas o grupo 2 de filtros obteve resultados de acordo com o padrão de reuso USEPA (2012) para o parâmetro de DBO. No grupo 1, apenas o filtro de 3 polegadas se apresentou em conformidade com tal padrão.

\section{Considerações Finais}

Os filtros de areia se apresentaram uma ótima alternativa para reutilização de águas cinzas sintéticas, pois além de promover alta eficiência de remoção da DBO e DQO, auxiliam na diminuição do uso da água potável por meio da reutilização de uma água com qualidade inferior e tornam atrativos os investimentos do sistema por apresentar procedimentos simples e baixo custo de implantação. Demonstram-se uma maneira válida para testes e aprimoração de trabalhos desenvolvidos no Brasil, para o tratamento de efluentes domésticos. No entanto, cabe frisar que é imprescindível e ideal a criação de leis específicas para águas residuárias como a água cinza, no Brasil.

Para os parâmetros analisados, DBO e DQO, os dois grupos de filtros se apresentaram eficientes para o tratamento da água cinza sintética, apresentando eficiência de remoção acima de $80 \%$, o que os tornam um tratamento viável. No entanto, para indicar seu uso propriamente dito são necessárias análises adicionais como os parâmetros de turbidez, sólidos dissolvidos, $\mathrm{pH}$, etc. com o intuito de validar a reutilização dos filtros para o reuso.

Recomenda-se a realização de estudos mais aprofundados para a avaliação de outras propriedades destes equipamentos no tratamento de águas cinzas.

\section{Referências}

ABNT; Associação Brasileira de Normas Técnicas. NBR 13.969 - Tanques sépticos: unidades de tratamento complementar e disposição final dos efluentes líquidos, projeto, construção e operação. Rio de Janeiro (Brasil): ABNT; 1997.
ABNT; Associação Brasileira de Normas Técnicas. NBR 15.527 - Água de chuva, aproveitamento de coberturas em áreas urbanas para fins não potáveis. Rio de Janeiro (Brasil): ABNT; 2007.

ALLEN L, CHRISTIAN-SMITH J, PALANIAPPAN M. Overview of greywater reuse: the potential of greywater systems to aid sustainable water management [Internet]. Califórnia: Pacific Institute; 2010 [cited 2017 Feb 15]. Available from: http://pacinst.org/reports/greywater_ overview/greywater_overview.pdf.

BOLLER M. Filter mechanisms in roughing filters. IRC Supporting water sanitation and hygiene services for life [Internet]. 1993 Jan 01. Available from: https://www. ircwash.org/resources/filter-mechanisms-roughing-filters.

BRUURSEMA T. The new NDF 350 and 350-1. Plumbing Systems \& Design [Internet]. 2011 Oct [cited 2017 Feb 15]. Available from: https://www.nsf.org/newsroom_pdf/ SU_PSD_Magazine_Article_LT_EN_350_351_LSU-27220911.pdf.

CARVALHO NL, HENTZ P, SILVA JM, BARCELLOS AL. Reutilização de águas residuárias. Revista do Centro de Ciências Naturais e Exatas. 2014;14(2): 3164-3171.

CHIN WH, RODDICK FA, HARRIS JL. Greywater treatment by UVC/ $\mathrm{H}_{2} \mathrm{O}_{2}$. Water Research. 2009;43(16):39403947.

DULTRA FA. Aplicação da filtração intermitente em leito de areia e de escória da metalurgia do cobre no tratamento de esgotos com ênfase em reuso [dissertation]. Salvador: Escola Politécnica/UFBA; 2017. 150 p.

GONÇALVES RF. Gerenciamento de águas cinzas. In: Gonçalves RF, editor. Uso Racional das Águas em Edificações. Rio de Janeiro: ABES; 2006. p. 153-222.

JEFFERSON B, LAINE A, PARSONS S, STEPHERSON T, JUDD S. Technologies for domestic wastewater recycling. Urban Water. 1999;1(4):285-292.

MORELLI EB. Reuso de água na lavagem de veículos [dissertation]. São Paulo: Escola Politécnica/USP; 2005. 107 p.

RESOLUÇÃO N. 54 DE 28 DE NOVEMBRO DE 2005. Estabelece modalidades, diretrizes e critérios gerais para a prática de reuso direito não potável de água, e dá outras providências. Diário Oficial da União (Brasília). 2017 Nov 19.

SABBAH I, GHATTAS B, HAYEEK A, OMARI J, HAJ Y, ADMON S, GREEN M. Intermittent sand filtration for wastewater treatment in rural areas of the Middel East - a pilot study. Water Science and Technology. 2003;48(11-12):147-152. 
SODAMADE G, LONGE E, SANGODOYIN A. Depth and performance evaluation of a laboratory scale sand filtration system for wastewater treatment. Turkish Journal of Engineering and Environmental Sciences. 2015;38(2):209-216.

TERPSTRA PMJ. 1999. Sustainable water usage systems: models for the sustainable utilization of domestic water in urban areas. Water Sci. Technol. 1999;39(5): 65-72.

UNITED STATES ENVIRONMENTAL PROTECTION AGENCY (USEPA): Guidelines for water reuse. U.S. Washington (EUA): Environmental Protection Agency, 2012. $643 \mathrm{p}$. 